\title{
Entrevista con Ana Ayllón Directora de la Escuela Libre Micael de pedagogía Waldorf
}

\author{
Miriam Gómez Soto y Carmen Viejo Díaz \\ Universidad de Alcalá de Henares
}

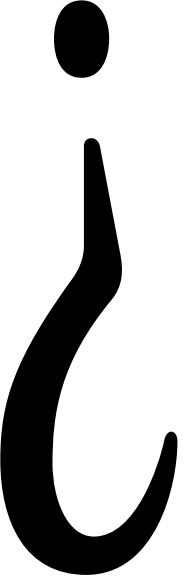

Cuándo comenzó a implementarse la metodología Waldorf de educación en España?

La pedagogía Waldorf nace en España en el año 1979 cuando en estos terrenos en los que se encuentra la escuela, comienza un jardín de infancia con siete niños. Nos encontramos entonces en plena transición, cuando nacen o tienen cabida las asociaciones. En aquel momento tres personas pioneras en esta pedagogía comienzan a trabajar con estos siete alumnos. Poco a poco va creciendo el número de niños, dando lugar a la creación de la primera asociación de padres y maestros de España, con el objetivo de que haya una escuela Waldorf en todos sus grados; la escuela Libre Micael.

Siete años después, en 1986, se inauguró la Educación Primaria con $1^{\circ}, 2^{\circ}$ y $3^{\circ}$. Los niveles se fueron ampliando hasta que hace cuatro años comenzamos con el bachillerato. Actualmente contamos con todos los niveles educativos.

¿Cuáles son los principios y fundamentos de la pedagogía Waldorf? Se basa en la observación del niño en todas sus etapas evolutivas desde los 0 a los 21 años. Se tiene presente qué es lo que necesita en cada edad el alumno para desarrollarse de una manera sana y equilibrada. A partir de ahí, se construye la educación, no sólo en el ámbito de su pensar sino también en el mundo anímico y de su voluntad.

El objetivo de la pedagogía es acompañar al alumno en su desarrollo, que se pueda convertir en un hombre libre, que piense con juicio propio, con equilibrio en lo anímico y en lo social, y que cuente con la fuerza de voluntad necesaria para llevar a cabo aquello que se proponga. Se parte de qué precisa el niño, no de lo que el Curriculum me dice que le tengo que dar, esto es muy importante. Se respeta el contenido del Curriculum, pero se procede al proceso de enseñanza partiendo de las necesidades del alumno.

¿Cuáles son las características que diferencian las escuelas Waldorf de las tradicionales según las diferentes etapas educativas? Hay varios elementos que las diferencian. Desde la Educación Infantil hasta los 7 años destaca la concepción de que el niño en esa etapa no necesita aprender a leer o escribir idiomas. ¿Qué es lo que quiere el niño a esa edad? iJugar! Todas sus capacidades futuras en cuanto a pensar o a relacionarse socialmente, se ba-
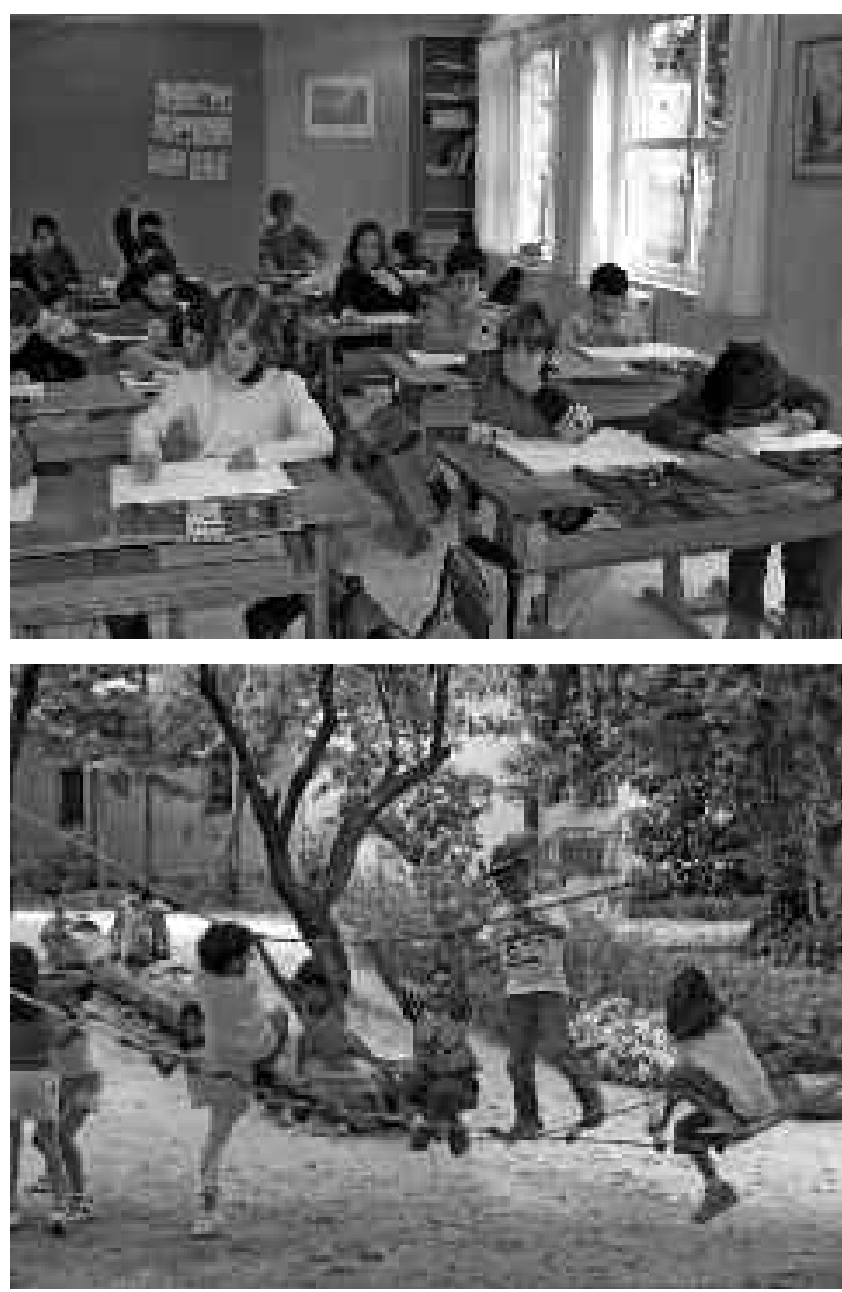

san en el juego, en el ritmo, la imitación. Desde la pedagogía Waldorf, se intenta preservar al niño en los primeros años de su infancia con el fin de no introducir en él una pre-lectura o pre-escritura precoz, bajo nuestro punto de vista.

Por otro lado destacaría el ambiente del jardín de infancia. En él los niños no están en cada clase por edad, están unidos de forma mixta desde los 3 a los 6 años, donde el elemento social juega un papel muy importante. Los mayores ayudan y aprenden a respetar a los pequeños y los pequeños aprenden de sus mayores.

El niño tiene cada día 90 minutos de juego libre. Cosa que ayuda al desarrollo de la psicomotricidad gruesa. El niño tie- 
Esta entrevista tuvo lugar en la Escuela Libre Micael, situada al norte de Madrid, en Pinar de las Rozas. Cuenta con $15.000 \mathrm{~m} 2$ de superficie y las instalaciones adecuadas para los más de 400 alumnos con los que cuenta. Es una de las ocho escuelas de primaria en España de pecdagogía Waldorf,y la única con Educación Secundaria y Bachillerato.

Ana Ayllón, directora del centro, nos acogió con gran amabilidad y entusiasmo, abriéndonos las puertas de su centro, atendiendo nuestras cuestiones y mostrándonos las instalaciones y materiales con los que ahí se trabaja.

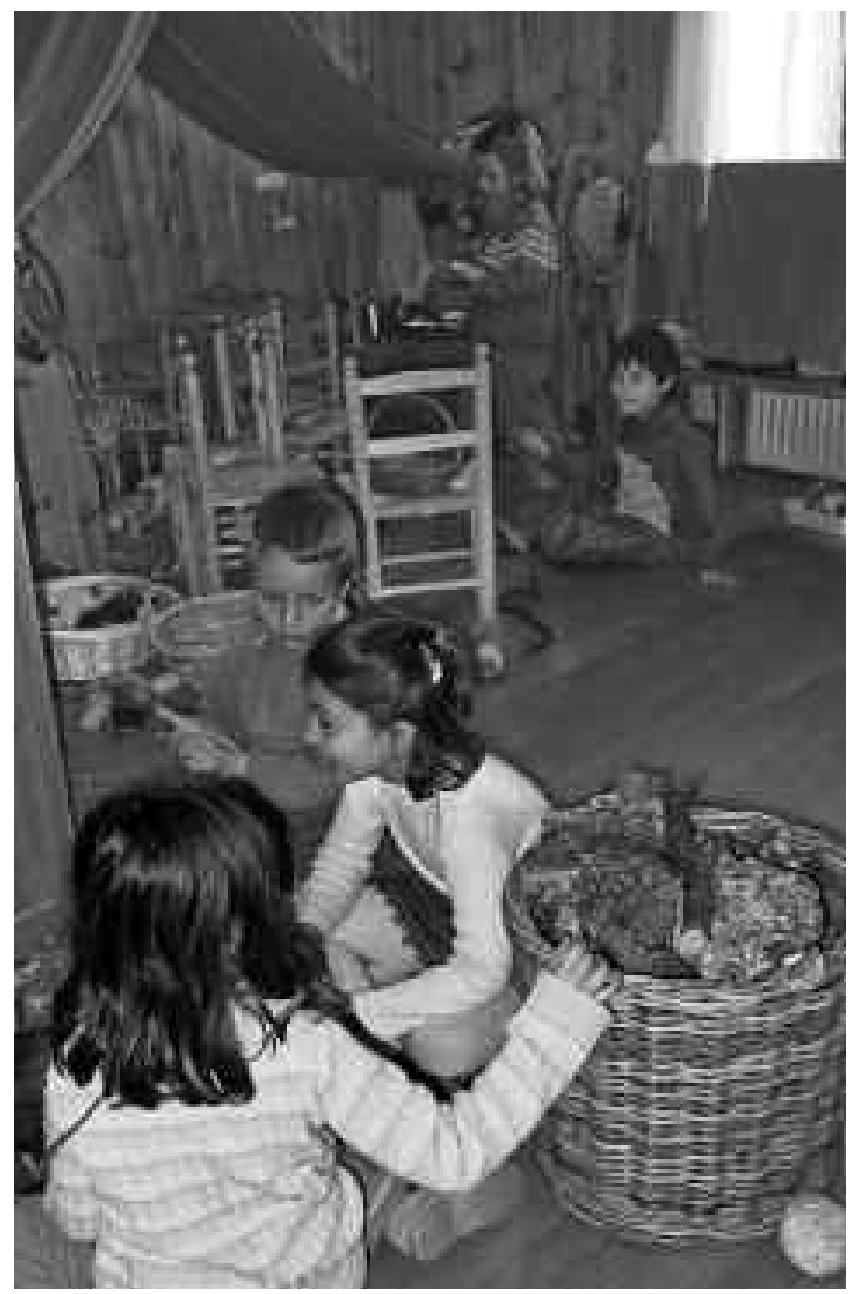

ne a su disposición todos los elementos de la naturaleza que se encuentran en el entorno del colegio, trepa los árboles, sube por cuerdas... Se intenta que desarrolle todo esto ahora, que es cuando le corresponde y no cuando sea adolescente.

En la etapa de toda la Educación Primaria hay dos elementos muy claros, el arte y la música. Un niño de Primaria no es como un niño de 16. Observa su alrededor de otra manera; las flores, las plantas, los árboles, las personas. Para desarrollar la motricidad fina, todos los niños hacen punto y trabajos manuales. El elemento artístico es clave en su desarrollo, se encuentra en los cuadernos o en las cosas que ellos mismos crean. Por ejemplo, en zoología, ellos mismos modelan los distintos animales, lo hacen en talla y luego lo pintan. Se busca una vivencia que no sólo sea intelectual para el niño, sino que sea vivencial a través del arte.

Por otro lado está el elemento social a través de la música. No sólo por el elemento formativo individual que tiene la música sino por el elemento social. A partir de $4^{\circ}$ de primaria, cuando tienen miniorquesta, saben que lo que uno hace es fundamental para el grupo. Es una forma de trabajar ese elemento inherente social donde tú, como maestro, no dices nada pero lo estás trabajando todo el tiempo, de manera inconsciente para el niño pero consciente por parte del profesor. Se trabaja mucho el movimiento, el ritmo, en todas las disciplinas, por ejemplo en matemáticas aprenden las tablas de multiplicar saltando a la comba. Se introduce el conocimiento no sólo a partir de algo que es conceptual, sino con canciones, con un poema, recitados... Esto permea en el niño de otra manera.

También contamos con un coro obligatorio para alumnos, tanto de primaria como secundaria. El año pasado hicimos un concierto benéfico para una ONG de África en un conservatorio de Madrid. Siempre intentamos cuidar ese vínculo con lo social.

En la etapa de la ESO el alumno empieza a desarrollar todo su juicio crítico y necesita tener sus propias opiniones y criterios. El camino que se hace con ellos transcurre a través de la ciencia, de la literatura, de la historia... Intentamos educar el pensar del alumno para que tenga su propio juicio. En el ámbito científico, no damos una ley de física diciendo ${ }$ Esta es una ley de física y se aplica así!» Sino que se presentan experimentos que ellos observan y describen, para después elaborar sus propias conclusiones, es decir, están acostumbrados a obtener su propia verdad.

Este es el camino que intentamos seguir con ellos para luego ofrecerles toda una serie de actividades prácticas que les permitan vincularse con el mundo.

Así, en $7^{\circ}\left(1^{\circ} \mathrm{ESO}\right)$, hacen un 'bloque de perspectiva', en $8^{\circ}$ $\left(2^{\circ} \mathrm{ESO}\right)$ tienen todo un trimestre un teatro donde se intenta acompañar todo su momento vivencial, en $9^{\circ}\left(3^{\circ} \mathrm{ESO}\right)$ van a una granja para hacer prácticas, en $10^{\circ}\left(4^{\circ} \mathrm{ESO}\right)$ hay una semana de prácticas de agrimensura, donde vamos al campo con toda la clase. En esta salida ellos forman los grupos de trabajo, y de manera autónoma, se reparten las tareas. Un grupo está en cocina y otros en el campo pero van rotando. Finalmente construyen un mapa del terreno todos los grupos juntos, el 
objetivo de esta etapa es lo social, que entre ellos interactúan, se pongan límites... trabajando esto con una actividad muy objetiva, que es medir.

En la clase 11 ( $1^{\circ}$ Bachillerato) hacen dos semanas (una de ellas de sus vacaciones) de prácticas sociales en instituciones que ellos mismos eligen; hospitales, residencias de ancianos, escuelas infantiles, escuelas con discapacitados... Buscan esos vínculos que llevan a esas grandes preguntas existenciales ¿cuál es mi lugar en el mundo?

En la clase 12 ( $2^{\circ}$ bachillerato) trabajamos la preparación para la selectividad y hacemos un viaje de arquitectura buscando la huella que el hombre ha dejado a lo largo de la historia, y cómo eso tiene que ver conmigo como individuo.

\section{En relación a los horarios, ¿son flexibles o los mantenéis fijos?}

Nuestro horario es fijo siempre, pero hay muchas cosas que van cambiando. Las clases del colegio, excepto Infantil, tienen una primera franja de la mañana que la llamamos clase principal. Son 2 ó 2 horas y media que van siendo ocupadas por distintos periodos lectivos que van cambiando a lo largo de los trimestres. Por ejemplo, ahora una clase ha empezado con lengua, y tendrá sólo clases de lengua en esa franja horaria durante 3 ó 4 semanas, de esta manera los alumnos penetran totalmente en la materia. Luego, por ejemplo, biología otras 3 o 4 semanas y así con el resto de disciplinas. Yo lo he visto con mi hija, es como si todo su ser estuviera permeado. Siempre hay unas semanas de matemáticas y lengua por trimestre.

Tras esta clase principal, el resto de la mañana tienen lugar las clases de euritmia, educación física, talleres... Las actividades manuales están siempre presentes, tienen talla, horticultura... En $8^{\circ}\left(2^{\circ}\right.$ ESO) cuentan con una segunda franja de tres semanas en la que hacen trajes y pintura en dos grupos que se turnan y doce semanas de taller de teatro, preparando obras que eligen alumnos y profesor de manera conjunta, este año prepararán una adaptación de El Quijote. En el último trimestre tienen un taller de naturaleza, donde observan y describen cualquier elemento que en ella encuentran; animales, plantas... Digamos que no es un libro quien les llena con algo, sino la propia vivencia. Son ellos quienes hacen su propio libro. En los cursos superiores se trabaja de forma similar, van alternando el arte con la tecnología.

No hay flexibilidad horaria en las «casillas» del horario, sino en lo que se sucede dentro del aula. Todo en el aula es bastante dinámico. Digamos que es algo fijo pero que cambia.

\section{¿Puede un niño con discapacidad asistir a una escuela Waldorf?}

Sí claro, cómo no. En la pedagogía Waldorf hay algo armonizador, terapéutico. En nuestro centro tenemos niños con altas capacidades y el caso contrario. Generalmente un niño con altas capacidades suele estar más polarizado con el conocimiento y la investigación, pero suele presentar dificultades con lo social, relacional, artístico o con lo motor. Aquí, al tratar todas las disciplinas y buscar, sobre todo, el elemento artístico se permite que el niño se vaya poco a poco equilibrando. Nosotros no contamos con alumnos de Educación Especial pero tenemos niños con Coeficiente Intelectual por debajo de la media. Las actividades plásticas, musicales, el teatro o euritmia son una forma de trabajar la capacidad de expresión. En ocasiones no alcanzan los contenidos matemáticos, pero al ofrecer una variedad tan grande de actividades, el niño siempre tiene cabida para decir en un lugar: «en esto valgo».

Por otro lado, existe todo un camino que es la pedagogía curativa, dirigida a personas con necesidades educativas especiales (ACNEES) donde hay niños y adultos. Hay centros subvencionados en Pozuelo y Villalba que trabajan con adultos. En ellos, se trata de desarrollar en el individuo las mejores capa-

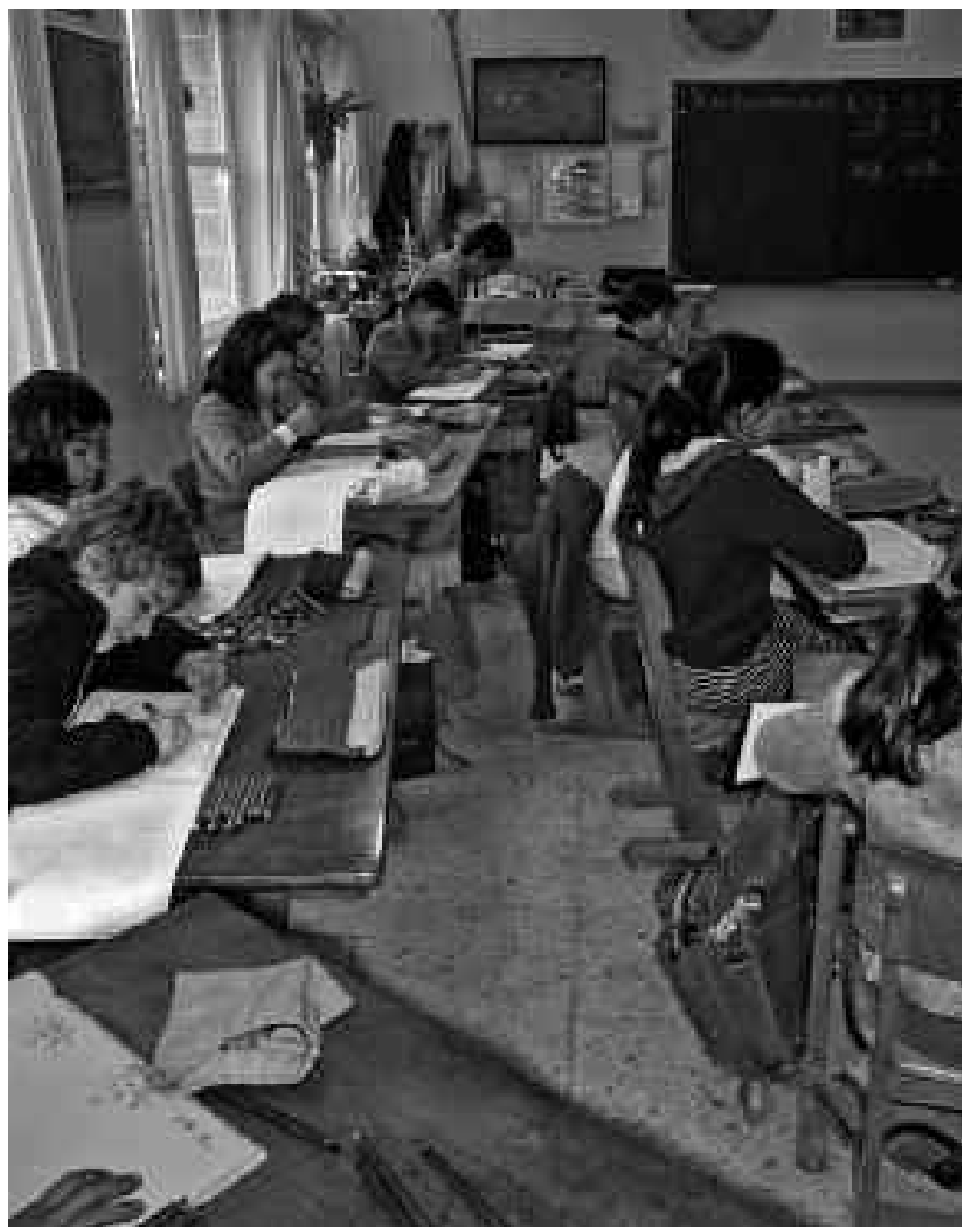

cidades trabajando con ritmos. A nuestro centro vienen a veces alumnos mayores de estos centros y desarrollan una actividad en forma de reto; presentar una obra de teatro. Nuestros alumnos quedan sobrecogidos por ese esfuerzo tan grande que hacen. También van alumnos de nuestra escuela a estos centros, de visita, e incluso muchos alumnos mayores acompañan proyectos de teatro con discapacitados, en iniciativas personales o institucionales, acudiendo una o más veces por semana, como voluntarios

Se busca una conexión con el mundo, no con lo que creemos que es el mundo, sino con lo que el mundo es, desde una mirada holográfica, estamos en ese intento. 
ciaciaciones de padres y maestros. La Escuela

Waldorf de Aravaca es una SL.con supropiages-

tión. Cada escuela se gestiona de manera libre e

independiente, el punto clave es la autogestión.

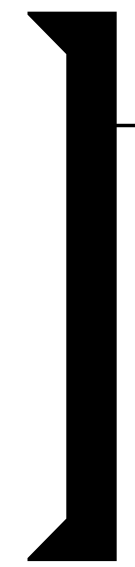

contigo no contra ti», este aspecto es el que más les cuesta encajar al marchar.

Tenemos alumnos que, yéndose fuera, han sacado matrícula de honor en $2^{\circ}$ bachillerato, otros que han repetido, también contamos con casos en los que no se han encontrado y al cabo de un año han decidido volver. Incluso tenemos antiguos alumnos trabajando en el colegio como docentes, licenciados en $\mathrm{Ma}-$ temáticas, Filología, Filosofía y Bellas Artes.

Tenemos un abanico multidisciplinar de todo tipo, donde nuestros alumnos han acabado trabajando en diferentes disciplinas.

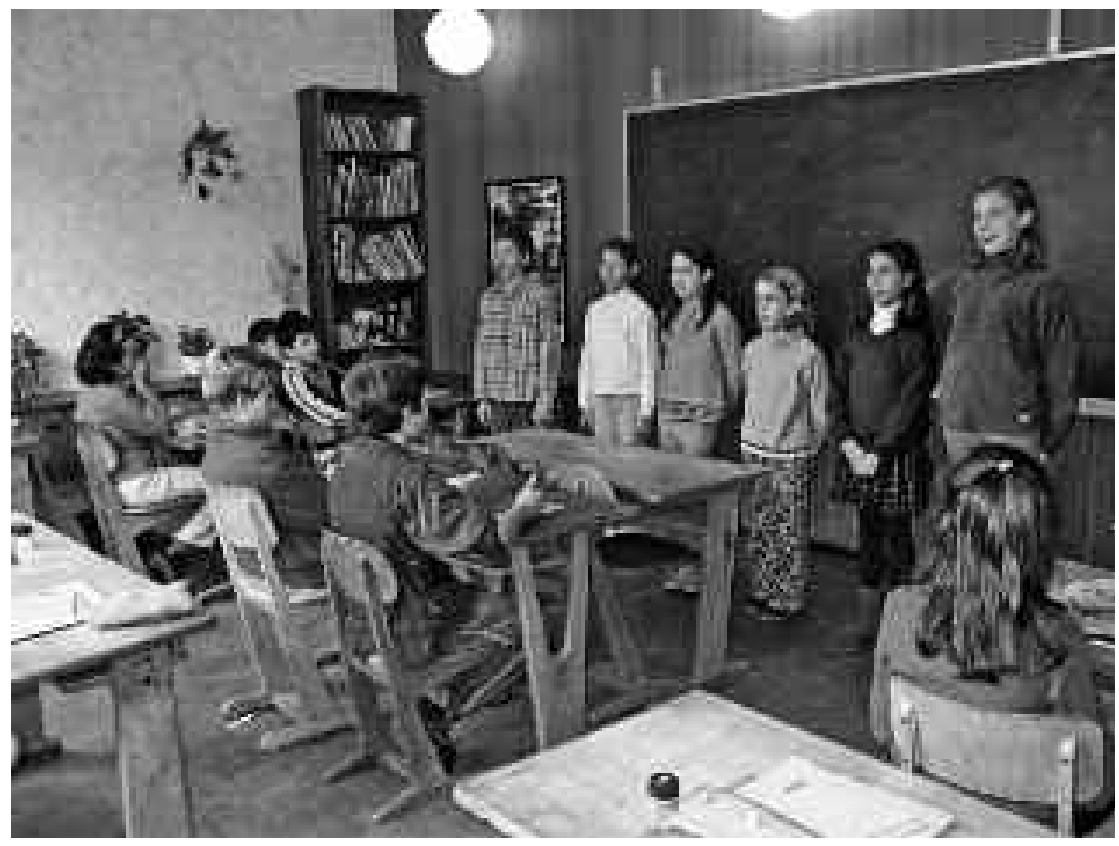

¿Todas las escuelas Waldorf son iguales?

No, tienen pilares comunes, como la observación del niño y el hecho de acompañar el Currículo con todo lo que el niño necesita para desarrollarse de manera saludable, en el pensar, en el sentimiento y en su voluntad, esa es la base.

Cada escuela Waldodf se crea de manera independiente, con un impulso que puede venir de maestros, padres y a veces mixto (maestros y padres juntos). Tiene su propio sistema autónomo para regirse y llevar adelante su Currriculum, no hay ningún elemento de franquicia, no podrás ver las paredes pintadas iguales, mobiliario...etc. Son señas de identidad de la pedagogía más que una línea organizada que deba seguirse.

La Escuela Libre Micael es una asociación de padres y maestros. La Escuela Waldorf de Aravaca es una sociedad limitada que tiene su propia gestión. La Escuela Artabán es una asociación de padres y maestros también. Ca-

Supongamos que un alumno, tras asistir a una escuela de pedagogía Waldorf, por cualquier eventualidad, tuviese que cambiar a una escuela de pedagogía tradicional, ¿qué sucedería frente a semejante cambio?

Hay un periodo de adaptación, en general es un trimestre. Hay muchos que se adaptan muy bien y a otros les cuesta mucho. Lo que más les choca de la pedagogía tradicional es el hecho de tener libros, que todo viene dado y no lo hacen ellos. También les cuesta adaptarse al horario convencional de asignaturas, seguidas de forma dispar en el mismo día, no como aquí donde tienen, por ejemplo, matemáticas durante tres semanas.

Otra de las dificultades de adaptación es el hecho de rellenar libros en lugar de hacer un resumen de lo que el maestro ha contado por la mañana. Lo primero es más dirigido y con «huecos». También tenemos el caso contrario, cuando un alumno viene de fuera le cuesta adaptarse aquí, a no tener un libro, a que el libro se vaya haciendo de manera conjunta en clase... Los alumnos se adaptan. Generalmente es más fácil la adaptación de un alumno que viene de otra escuela a la pedagogía Waldorf.

Hemos tenido alumnos que les ha costado adaptarse en lo anímico. Sobre todo en los adolescentes, es una época difícil. Aquí siempre mantienes un vínculo entre alumno y profesor, existe una raya; "hasta aquí puedes llegar, pero estoy da escuela se gestiona de manera libre e independiente, el punto clave es la autogestión.

Hay un elemento muy central en todas las escuelas que es el claustro de maestros, el corazón de la escuela, y en él no hay una estructura piramidal.

Soy directora pero yo más bien estoy al servicio de lo que hace falta para coordinar, no decido lo que se va a hacer y cómo. Pregunto: ¿cómo queréis que hagamos esto? ¿De qué manera podríamos hacerlo? Evidentemente, hay cuestiones técnicas que he de atender como directora, yo firmo los contratos y a la hora de tomar la decisión de algo tengo todas las responsabilidades jurídicas y económicas. Pero tomo las decisiones junto con el equipo de dirección y el consejo administrativo, intentamos buscar siempre ese elemento más circular y horizontal que piramidal.

\section{A pesar de que cada escuela se autogestione, ise relacionan unas con otras? ¿Mantienen el contacto de alguna manera?}

Sí. Existen encuentros de maestros en Europa. Por ejemplo, yo voy a los encuentros de profesores matemáticos de Waldorf. Además, cada cuatro años hay un encuentro internacional de maestros, al que acuden más de 1500 maestros de 90 países diferentes en los que está la pedagogía Walforf. De aquí vamos entre 10 y 20 profesores, y ponemos en común lo que pasa en $\mathrm{Pa}$ - 
kistán, Israel, India, Brasil, Nueva Zelanda, Rusia...

También existen federaciones en España, hay una asociación de centros educativos Waldorf donde hay representantes de las distintas escuelas. Se intenta, de alguna manera, unir el reconocimiento de la pedagogía Waldorf como un elemento más dentro de las distintas pedagogías existentes y no con ello los criterios de cada centro.

\section{Dentro del mundo Waldorf, existe una disciplina artística denomina- da euritmia ¿Qué puedes contar de ella?}

La euritmia es un arte del movimiento que está basado en el lenguaje y la música. Cada fonema, cada vocal o consonante tiene un gesto natural, cuando tú dices por ejemplo "mamá» el gesto es mucho más emotivo y envolvente que si dices ¿qué quieres?.. Este es más como un imperativo «itú qué quieres!» es otro gesto. Cada letra tiene un gesto que corresponde para lo que nosotros es también esa letra. Si lo observamos un poco hay letras que son envolventes, otras son cortantes... Diríamos que el sonido da lugar a un gesto. Y lo mismo sucede con la música, con cada tono mayor o menor, cada intervalo... a partir de ahí podemos elaborar toda una interpretación artística de, por ejemplo, una sonata y ponerla en movimiento.

Esta actividad requiere mucha coordinación, geometría, movimientos y demás aspectos que se relacionan. La euritmia se trabaja desde pequeñito, a través de un cuento, hasta los mayores, quienes pueden hacer declamaciones de poemas o fábulas de la literatura española además de grandes piezas musicales como con las que actualmente están trabajando; sonatas de Schubert.

Se trabaja buscando el movimiento en el espacio, la pérdida del ridículo en el adolescente, la exactitud, la colocación...

Por ejemplo, los mayores trabajan con barras de cobre y, en muchas ocasiones, requieren de precisión en los lanzamientos para evitar peligros, se requiere conciencia y atención sin tener que estar diciendo: “iconcéntrate!» Se intenta, con estos elementos, que desarrollen estas capacidades, además de las de orientación, sociales, musicales... etc.

La euritmia es una carrera de 6 años y tiene una línea también terapéutica de otros 2 años más.

El multi-tasking es un fenómeno creciente en el mundo ¿Qué implicaciones crees que tiene en los procesos de aprendizaje para esta generación y las siguientes que serán «nativos tecnológicos» dentro de la pedagogía Waldorf?

En cuanto a las TICS, depende de cada escuela; nosotros en ésta no introducimos el uso del ordenador, pero sí enseñamos sistema binario, tablas de verdad eléctricas y circuitos integrados. El currículum Waldorf de los años superiores ha introducido la informática, con el objetivo de comprender cómo funciona un ordenador y poder programar en distintos sistemas, y no solo emplearlo como usuario

Como docente, el hecho de traer toda la clase prefijada y elaborarla de manera previa a partir de búsqueda en bancos de datos, no me parece educativo según mi opinión. Yo voy a clase y construyo la clase, les miro, les pregunto "¿cómo ha ido con lo de ayer?" Ellos me comentan qué necesitan y lo que trabajamos me da igual hacerlo con lápiz óptico que pizarra di- gital o tradicional. No es lo que usas sino cómo lo usas.

Comparto que se puedan usar como herramienta, todos los alumnos tienen smartphone, blackberry, ordenador... pero en lo referente a la escuela lo usan como herramienta de búsqueda.

No hay que perder de vista lo que es el punto de encuentro entre maestro y alumno.

Enseñar no es traer mi clase prefijada y darla. El niño tiene que desarrollar muchas habilidades motrices y motoras que tienen que ver con el aprendizaje de la escritura en sí como elemento educativo. Los niños nos dan mil vueltas en el manejo de tecnologías, pero ¿qué aporta en el desarrollo de capacidades un ordenador a un niño de 5 años?

Yo soy muy tecnológica, aquí lo somos como centro en la administración, para el funcionamiento diario, incluso con los alumnos para comunicarnos.

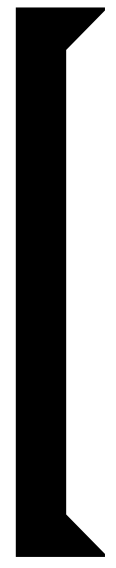

El currículum Waldorf de los años superiores ha introducidolainformática,conelobjetivodecomprender cómo funciona un ordenador y poder programar en distintos sistemas, y no solo emplearlo como usuario.

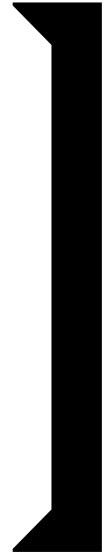

Quizás estemos atascados, porque somos estructuras que buscamos preservar en un determinado ambiente, a pesar de que los alumnos lo tienen siempre en su casa. Los de bachillerato se comunican por correo, hacen trabajos y se los mandan.

No es tanto un rechazo hacia las TIC, sino una observación de ¿A qué edad? ¿Qué buscas? ¿Para qué? ¿Cómo utilizarlas?...

En otras escuelas de Waldorf de EEUU, sí integran la tecnología en las clases, son muy elitistas y cuentan con muchos recursos.

\section{Existen posturas que critican el acceso preferente a la escuela Wal- dorf de la clase social alta, ligando este hecho a la creencia de que Rudolf Steiner era antisemita y racista}

Vamos por partes. Lo de las clases sociales depende de los países, en España, por ejemplo sólo hay una escuela de pedagogía Waldorf concertada. El resto, incluyendo ésta, son privadas porque la concertación exige una serie de requisitos, sobre todo uno fundamental, como es el sistema de baremación del centro. Aquí tenemos alumnos que vienen desde Guadalajara, los cuales no podríamos tener ajustándonos a dicha baremación. Somos la única escuela que tiene bachillerato y concertarla sería, en parte, limitarla.

Si una familia de verdad quiere venir, puede. Ahora mismo en nuestra escuela hay muchas familias becando a otras. Entre 5 familias pagan una cuota de un niño u otra familia paga íntegramente el coste de un alumno. Hay un sistema social muy 


\section{En Europa las escuelas Waldoof dependen de los} países, y reciben subrenciones del setenta al noventa por cien del estado, es decir, te financian tus costes. De esta manera, acceden familias de toda indole, familias de clase elevada, media y baja. tenidas por otras personas, maestros, amigos. Hay maestros que donamos, es así. Es la conciencia que vive en la escuela.

En lo concerniente a las ideas antisemitas de Steiner, quizá estemos hablando de alguna creencia que corre por ahí. Él dijo que la escuela debe ser mixta, mientras que en España no lo eran todavía. Las escuelas Waldorf fueron cerradas por Hitler porque promovían la libertad del individuo, justo lo contrario sobre lo que el nazismo buscaba.

En ocasiones aparecen estas ideas, se les trata a las escuelas de «sectarias», incluso los alumnos mismos dicen «la secta esta» por el hecho, quizás, de que son diferentes, de que hay color, de que los alumnos hacen euritmia y, a veces, en las representaciones, llevan trajes o túnicas de otra época.

Todo lo que proviene de Steiner, en todos los ámbitos en los que participó, partiendo de la concepción del hombre como filosofía y aplicándolo posteriormente a la pedagogía, a la medicina, la agricultura, biodinámica o agricultura ecológica... ¿Qué es lo que promueve? Un respeto por la tierra, y no lo contrario. Lo mismo sucede con la educación, el objetivo es educar al hombre como un ser humano libre, para mí es muy claro el criterio.

\section{Bibliografía:}

Aula de Innovación Educativa n ${ }^{\circ} 119$. Febrero de 2003. «La educación integral: las prácticas waldorf».

http://www.centrowaldorf.com/bibliografia.htm

Enlaces de interés:

http://www.escuelamicael.com

http://www.colegioswaldorf.org

http://www.centrowaldorf.com

\section{Die DaF-Familie wächst}

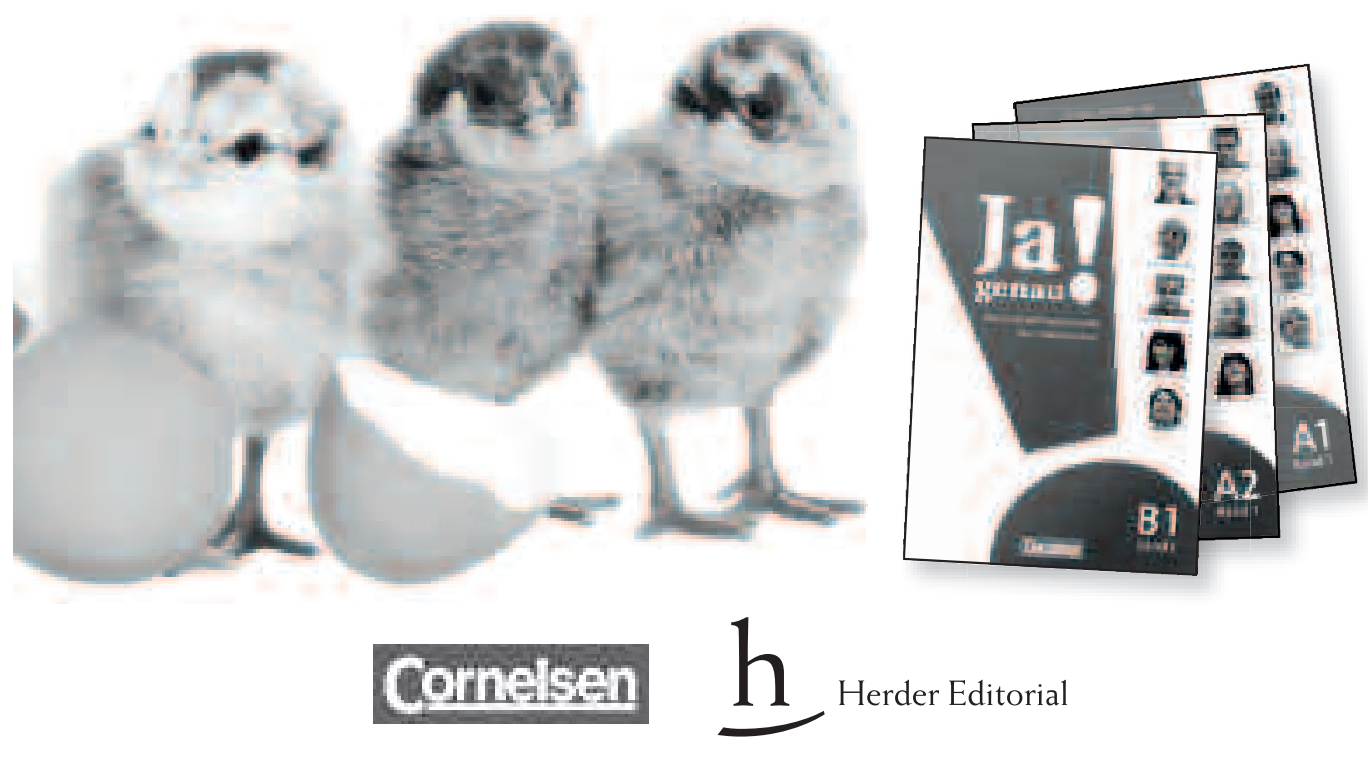

Weitere Informationen erhalten Sie bei Moritz Alber, email: idiomas@herdereditorial.com Mobil: 618299896 